\title{
Infant gut microbiota and the hygiene hypothesis of allergic disease: impact of household pets and siblings on microbiota composition and diversity
}

Meghan B Azad ${ }^{1}$, Theodore Konya ${ }^{2}$, Heather Maughan ${ }^{3}$, David S Guttman ${ }^{3}$, Catherine J Field ${ }^{4}$, Malcolm R Sears ${ }^{5}$, Allan B Becker ${ }^{6,7}$, James A Scott ${ }^{2}$, Anita L Kozyrskyj ${ }^{1,7^{*}}$ and CHILD Study Investigators

\begin{abstract}
Background: Multiple studies have demonstrated that early-life exposure to pets or siblings affords protection against allergic disease; these associations are commonly attributed to the "hygiene hypothesis". Recently, low diversity of the infant gut microbiota has also been linked to allergic disease. In this study, we characterize the infant gut microbiota in relation to pets and siblings.

Methods: The study population comprised a small sub-sample of 24 healthy, full term infants from the Canadian Healthy Infant Longitudinal Development (CHILD) birth cohort. Mothers reported on household pets and siblings. Fecal samples were collected at 4 months of age, and microbiota composition was characterized by high-throughput signature gene sequencing.

Results: Microbiota richness and diversity tended to be increased in infants living with pets, whereas these measures were decreased in infants with older siblings. Infants living with pets exhibited under-representation of Bifidobacteriaceae and over-representation of Peptostreptococcaceae; infants with older siblings exhibited under-representation of Peptostreptococcaceae.

Conclusions: This study provides new evidence that exposure to pets and siblings may influence the early development of the gut microbiota, with potential implications for allergic disease. These two traditionally protective "hygiene hypothesis" factors appear to differentially impact gut microbiota composition and diversity, calling into question the clinical significance of these measures. Further research is required to confirm and expand these findings.
\end{abstract}

Keywords: Infants, Gut microbiota, Gut microbiome, Hygiene hypothesis, Microflora hypothesis, Pets, Siblings, Atopy, Allergic disease, Environmental exposures

\section{Background}

In recent decades, dozens of studies from around the world have reported that early-life exposure to pets or older siblings is protective against the development of allergic disease [1-4], and these associations are commonly attributed to the "hygiene hypothesis". In its original form, this hypothesis claims that limiting early-life infection impedes natural immune system development and causes predisposition to allergic disease [5]. The modified

\footnotetext{
* Correspondence: anitakozyrskyj@med.ualberta.ca

'Department of Pediatrics, University of Alberta, 3-527 Edmonton Clinic Health Academy 11405 - 87th Avenue, Edmonton, AB T6G IC9, Canada ${ }^{7}$ Manitoba Institute of Child Health, Winnipeg, Canada

Full list of author information is available at the end of the article
}

"microflora hypothesis" proposes that, rather than specifically limiting infection, the overly hygienic Western lifestyle limits general microbial exposure and alters the colonization of the infant gut, which in turn disrupts development of the immune system and ultimately leads to allergic disease [6].

In support of the microflora hypothesis, reduced gut microbiota diversity during infancy has been associated with allergic disease later in childhood [7-13]. One could speculate that this is a function of fewer microbes in the home environment; however, human and piglet studies indicate that greater microbe diversity in the environment actually leads to reduced diversity of the gut 
microbiota [14,15]. In some cases, the prevalence or relative abundance of specific organisms has been associated with atopic outcomes. For example, early-life colonization by Clostridium difficile reportedly increases risk for childhood wheeze, eczema and asthma [16], whereas certain Bifidobacteria and Lactobacilli are considered protective [8,17-19]. It therefore remains unclear whether diversity is paramount, or whether gut microbiota composition is more important for immune system development and avoidance of atopic disease.

Household pets and siblings are thought to protect against atopy by increasing contact with environmental microbes during early life, thereby promoting a diverse and healthy gut microbiota. While associations of pets and siblings with atopy have been reported (and debated) for decades [1-5,20,21], few studies have directly evaluated the gut microbiota as a mediator. There is only limited evidence that contact with siblings influences the gut microbiota [22,23], and no studies have evaluated the role of pets.

In this study, we aimed to determine the impact of two early-life exposures traditionally associated with the hygiene hypothesis, pets and siblings, on the diversity and composition of infant gut microbiota.

\section{Methods}

\section{Study design}

This descriptive study of 24 infants represents a subset of the larger CHILD (Canadian Healthy Infant Longitudinal Development) national population-based birth cohort (www.canadianchildstudy.ca). Participants were enrolled in Winnipeg, Manitoba between November 2008 and August 2009. Mothers completed standardized questionnaires which addressed household pets, siblings, breastfeeding, infant medications, maternal atopy and education. Mode of delivery was obtained from hospital birth records. Written informed consent was obtained from parents at enrollment. This study was approved by the University of Manitoba Human Research Ethics Board.

\section{Sample collection, DNA extraction and amplification}

Fecal samples were collected from 3-4 month old infants as part of a scheduled home visit. Samples were refrigerated during transport and then stored at $-80^{\circ} \mathrm{C}$. Whole genome DNA was extracted from $40 \mathrm{mg}$ of stool using the FastPrep DNA for Soil Kit (MP Biomedicals Inc, Solon, OH, USA) [24]. The bacterial 16S rRNA gene, hypervariable regions V5-V7, was amplified through PCR using primers optimized for gut-occurring taxa: 5'-GGGKAKCRAACVG GATTAGATACCCBGGTAGTCCWNRCHSTAAACGD TG-3' $(\mathrm{mV} 5+791)$ and 5'-GGSCRTRMKGAYTTGACG TCRYCCCCDCCTTCCTCC-3' (V7-1104). Optimization was achieved by modifying previously-described primers [25] to accommodate a polymorphism unique to the gut-associated genus Bifidobacterium; the modified base is underlined in the primer sequence above. The primers were barcoded so that each sample could be uniquely identified post-sequencing. Each PCR mixture $(50 \mu \mathrm{l})$ contained $5 \mu \mathrm{l} 10 \mathrm{X}$ Hotstart Buffer, $400 \mu \mathrm{M}$ dNTPs, $1.5 \mathrm{mM} \mathrm{MgCl}$, 2.5Uof Hotstart Taq polymerase (Fermentas, Glen Burnie, MD, USA), $0.02 \mathrm{mg}$ Ultrapure Bovine Serum Albumin (Ambion, Austin TX), molecular biology reagent grade water (SigmaAldrich, St. Louis, MO, USA), $0.16 \mu \mathrm{M}$ primer, and $2 \mu \mathrm{l}$ bacterial template DNA $(10 \mathrm{ng} / \mu \mathrm{l})$. The PCR program consisted of an initial DNA denaturation step at $94^{\circ} \mathrm{C}$ (4 min), followed by 18 cycles of DNA denaturation at $94^{\circ} \mathrm{C}(45 \mathrm{sec})$, an annealing step at $56^{\circ} \mathrm{C}$ (30 sec) and an elongation step at $72^{\circ} \mathrm{C}(2 \mathrm{~min} 30 \mathrm{sec})$, and was performed on the PTC-200 Peltier Thermal Cycler (MJ Research, St. Bruno, QC, Canada). The PCR product was cleaned with GENECLEAN ${ }^{\circ}$ Turbo Kit (MP Biomedicals Inc, Solon, OH, USA) and gel purified using the E-gel ${ }^{\circ}$ SizeSelect $^{\text {ti }} 2 \%$ agarose gel cutting system (Invitrogen, Carlsbad, CA, USA). Fifty nanograms of cleaned/extracted product from each sample was combined and concentrated for sequencing, using an Amicon $^{\circledR}$ Ultra-4 $30 \mathrm{~K}$ centrifugal filter (Millipore, Billerica, MA, USA).

\section{S rRNA sequencing and taxonomic classification}

Pooled PCR amplicons were sequenced at portions of the V5, V6, and V7 16S rRNA hypervariable regions using Serial Illumina Sequencing (SI-Seq) [25] at the University of Toronto Centre for the Analysis of Genome Evolution \& Function (CAGEF).

Reads were concatenated for a final length of $144 \mathrm{bp}$, and then processed through the SI-Seq analysis pipeline for de-barcoding and quality filtering, which removed reads having more than 10 sites with a Phred score less than 20 . The resulting high quality reads were denoised, cleared of chimeras, and clustered into operational taxonomic units (OTUs) using the otupipe scripts [26]. An empirically derived nucleotide identity threshold of $87 \%$ was used for OTU clustering [25]. One representative sequence from each OTU was classified according to the SILVA taxonomy by $95 \%$ identity (i.e., genus level) clustering with the SILVA database sequences [27] formatted to SI-Seq read structure. Within each sample, OTUs with abundances lower than $0.18 \%$ were removed from the analysis based on an empirically derived misclassification/sequencing error rate [25]. After cleaning and processing, a total of 2.86 million reads were retained (median $9.6 \times 10^{4}$ per sample, range $1.5 \times$ $\left.10^{4}-4.5 \times 10^{5}\right)$.

\section{Quantitative PCR}

We followed the method of Penders et al. for qPCR analysis of Clostridium difficile [23]. Oligonucleotides were 
manufactured by IDT (Integrated DNA Technologies Inc, Coralville, IA, USA). All reactions were performed on the MiniOpticon ${ }^{\text {TM }}$ Real-Time PCR System (Bio-Rad, Hercules, CA, USA).

\section{Statistical analysis}

In this descriptive paper, we report fecal microbiome biodiversity and relative abundance of bacterial taxa according to household pets and siblings. Biodiversity measures, the Chao1 estimator of species richness and the Shannon diversity index [28], were calculated using QIIME (http://qiime.org/) [29] with rarefied data (10,000 sequences per sample). These normallydistributed index measures were compared by twosided t-test. Differential abundance of bacterial taxa was assessed at the family and genus levels using Metastats (http://metastats.cbcb.umd.edu). Distribution of potential confounding variables according to pets or siblings was assessed by chi-squared test or Fisher's exact test, as indicated.

\section{Results}

\section{Study population}

Fecal samples were collected from 24 healthy full-term infants (mean age $17.4 \pm 3.2$ weeks). The study population (Table 1) comprised equal numbers of males and females. Thirteen infants (54\%) had at least one older sibling and 15 (63\%) lived in a household with pets (at least one cat or dog). At the time of sampling, 15 (63\%) infants were exclusively or partially breast-fed. Six infants were delivered by caesarean section and 3 infants had received antibiotics. There was no significant difference in the rate of breastfeeding, antibiotic use or caesarean delivery according to the presence of household pets or siblings.

\section{Fecal microbiota composition}

The relative abundance of dominant bacterial groups for each infant, as detected by $16 \mathrm{~S}$ rRNA sequencing, is shown in Figure 1A. Infant fecal microbiota were generally dominated by Actinobacteria (median 36.4\%, mainly the genus Bifidobacterium) and/or Firmicutes (median 43.8\%, with diverse representation from numerous genera). Proteobacteria were less abundant (median 7.4\%), though present in all subjects, whereas Bacteroidetes were detected in less than half (37.5\%) of the study population.

Despite high inter-subject variability, we were able to detect significant effects of exposure to pets and siblings on the relative abundances of several bacterial taxa (Table 2 and Figure 1B). We found that infants living with pets had significant over-representation of Clostridiaceae, Veillonella (especially for dogs), Peptostreptococcaceae and Coprococcus. Bifidobacteria were under-represented among infants living with pets (especially for cats). For dogs only, there was also under-representation of Eggerthella. Fewer differences were detected according to siblings; however, Peptostreptococcaceae were significantly under-represented among infants with older siblings. Similar trends were observed when examining the prevalence (rather than relative abundance) of bacterial taxa (Additional file 1: Table S1). For example, Peptostreptococcaceae were detected significantly more often among infants with pets compared to those without ( $67 \%$ vs. $11 \%, p=0.01)$. Stratified statistical comparisons of pets by siblings were not pursued due to small group sizes; however, we observed that infants exposed to both pets and siblings tended to have particularly low relative abundance of Bifidobacteriaceae (Figure 1A).

Because of its reported association with atopic outcomes [16], we also performed targeted qPCR analyses to detect colonization by $C$. difficile (a member of the

Table 1 Characteristics of study subjects

\begin{tabular}{|c|c|c|c|c|c|c|}
\hline \multirow[b]{2}{*}{ N (\%): } & \multicolumn{2}{|c|}{ Overall $(\mathrm{N}=24)$} & \multicolumn{2}{|c|}{ Households with pets $(\mathrm{N}=15)$} & \multicolumn{2}{|c|}{ Households with siblings $(\mathrm{N}=13)$} \\
\hline & & & & & & \\
\hline Gender; male & 12 & $(50.0)$ & 6 & $(40.0)$ & 7 & $(53.9)$ \\
\hline Caesarean Delivery & 6 & $(25.0)$ & 3 & $(20.0)$ & 3 & $(23.1)$ \\
\hline Breastfed & 15 & $(62.5)$ & 8 & (53.3) & 9 & $(69.2)$ \\
\hline Maternal Atopy & 9 & $(37.5)$ & 6 & $(40.0)$ & 6 & $(46.2)$ \\
\hline Siblings & 13 & $(54.2)$ & 6 & $(40.0)$ & - & \\
\hline Pets & 15 & $(62.5)$ & - & - & 6 & $(46.2)$ \\
\hline Infant antibiotics & 3 & $(12.5)$ & 2 & $(15.4)$ & 1 & (8.3) \\
\hline Maternal PS Education & 18 & (75.0) & 13 & $(86.7)$ & 9 & $(69.2)$ \\
\hline \multicolumn{7}{|l|}{ Mean (SD): } \\
\hline Birth Weight; g & 3441 & (493) & 3453 & $(551)$ & 3455 & (357) \\
\hline Gestational Age; wks & 39.2 & (1.6) & 39.3 & (1.4) & 39.5 & (1.2) \\
\hline
\end{tabular}

SD, standard deviation; PS, post-secondary. Comparisons by chi-squared test / Fisher's exact test, or t-test; no statistically significant differences observed. 

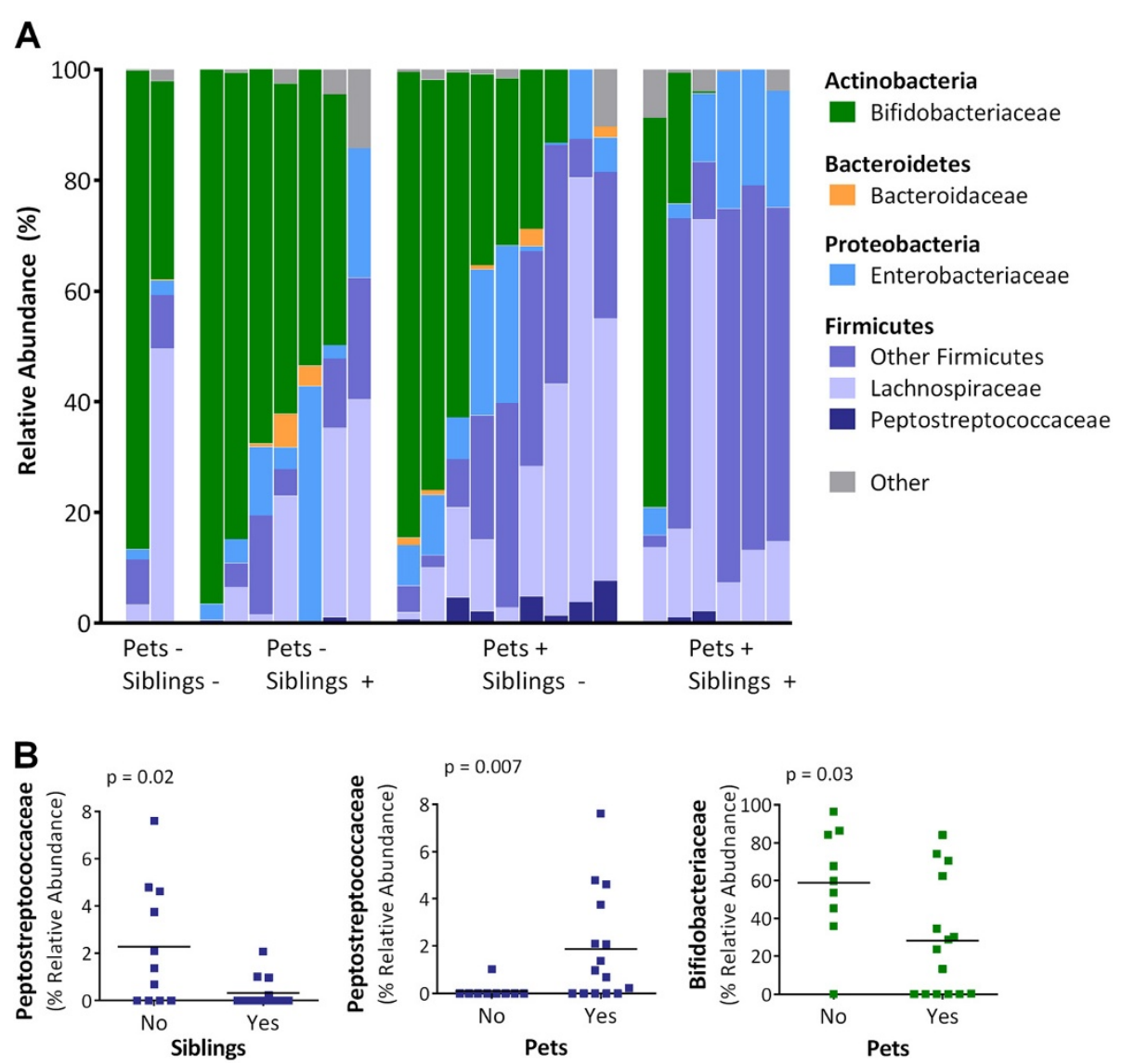

Figure 1 Fecal microbiota composition for 24 infants (mean age 4 months) according to the presence of household pets and siblings. A) Relative abundance of dominant bacterial families; each column represents one infant. B) Selected differentially abundant families according to pets and siblings; bars indicate means. Relative abundance determined by 165 rRNA sequencing; comparisons conducted with Metastats (see Methods and Table 2).

family Peptostreptococcaceae). Consistent with the antithetical associations observed for Peptostreptococcaceae relative abundance, $C$. difficile prevalence tended to be higher among infants with pets, and lower among infants with siblings: $C$. difficile was detected in $67 \%$ of infants with pets, compared with $22 \%$ of infants without pets $(\mathrm{p}=0.09)$, and $31 \%$ of infants with older siblings, compared with $73 \%$ of first-born infants $(\mathrm{p}=0.10)$. Comparison of $\mathrm{qPCR}$ and sequencing results revealed that sequencing-based analyses were highly specific and moderately sensitive for $C$. difficile. Two of seven Peptostreptococcaceae OTUs could be further classified as different strains of $C$. difficile; these OTUs were absent in all infants testing negative by qPCR $(100 \%$ specificity), and were detected in 8 of 12 infants testing positive (67\% sensitivity).

\section{Biodiversity}

Overall, the mean rarefied Chao1 score for species richness (which evaluates the number of different species present) was 12, ranging from 3 to 22 . The average Shannon diversity index (which accounts for both species richness and evenness) was 1.38 , ranging from 0.17 to 2.36 . Opposite trends in biodiversity were observed with respect to pets versus siblings (Figure 2 and Table 3). Although differences did not reach statistical significance, infants with pets tended to have increased microbiota richness and diversity, whereas these measures tended to be decreased in infants with older siblings.

\section{Discussion}

Using a comprehensive and culture-independent approach, we have characterized the impact of household pets and siblings on the composition and diversity of infant gut microbiota. Our findings suggest that these two traditionally protective "hygiene hypothesis" factors exert distinct effects on microbiota diversity, and select for different assemblages of gut microbes (Figure 3). These results imply that the "microflora hypothesis" of allergic disease is likely a function of complex changes in microbiota composition, rather than simplified variations in overall diversity. 
Table 2 Relative abundance of dominant bacterial taxa in infant stool, according to household pets and siblings

\begin{tabular}{|c|c|c|c|c|c|c|c|c|c|c|c|c|c|c|}
\hline \multirow[t]{3}{*}{ Taxon } & \multirow{2}{*}{\multicolumn{2}{|c|}{$\begin{array}{l}\text { Overall } \\
N=24\end{array}$}} & \multicolumn{3}{|c|}{ Older siblings } & \multicolumn{3}{|c|}{ Pets } & \multicolumn{3}{|c|}{ Dog } & \multicolumn{3}{|c|}{ Cat } \\
\hline & & & \multirow{2}{*}{$\begin{array}{c}\text { No } \\
n=11\end{array}$} & \multirow{2}{*}{$\begin{array}{c}\text { Yes } \\
n=13\end{array}$} & \multirow[t]{2}{*}{$\mathbf{p}$} & \multirow{2}{*}{$\begin{array}{c}\text { No } \\
n=9\end{array}$} & \multirow{2}{*}{$\begin{array}{c}\text { Yes } \\
n=15\end{array}$} & \multirow[t]{2}{*}{ p } & \multirow{2}{*}{$\begin{array}{c}\text { No } \\
n=12\end{array}$} & \multirow{2}{*}{$\begin{array}{c}\text { Yes } \\
n=12\end{array}$} & \multirow[t]{2}{*}{$p$} & \multirow{2}{*}{$\begin{array}{c}\text { No } \\
n=17\end{array}$} & \multirow{2}{*}{$\begin{array}{c}\text { Yes } \\
n=7\end{array}$} & \multirow[t]{2}{*}{$p$} \\
\hline & Mean & (SD) & & & & & & & & & & & & \\
\hline \multicolumn{15}{|l|}{ Actinobacteria } \\
\hline Bifidobacteriaceae & 39.6 & (33.4) & 40.9 & 38.6 & - & 58.8 & 28.1 & 0.03 & 46.7 & 32.6 & - & 48.0 & 19.3 & 0.03 \\
\hline Bifidobacterium & 39.6 & $(33.4)$ & 40.9 & 38.6 & - & 58.8 & 28.1 & 0.03 & 46.7 & 32.6 & - & 48.0 & 19.3 & 0.02 \\
\hline Coriobacteriaceae & 1.4 & (3.3) & 0.3 & 2.3 & 0.07 & 2.2 & 0.9 & - & 2.0 & 0.8 & - & 1.7 & 0.6 & - \\
\hline Eggerthella & 0.5 & $(1.0)$ & 0.3 & 0.6 & - & 0.7 & 0.3 & - & 0.8 & 0.1 & 0.01 & 0.4 & 0.6 & - \\
\hline \multicolumn{15}{|l|}{ Bacteroidetes } \\
\hline Bacteroidaceae & 0.8 & $(1.5)$ & 0.8 & 0.8 & - & 1.2 & 0.5 & - & 0.9 & 0.7 & - & 0.9 & 0.5 & - \\
\hline Bacteroides & 0.8 & $(1.5)$ & 0.8 & 0.8 & - & 1.2 & 0.5 & - & 0.9 & 0.7 & - & 0.9 & 0.5 & - \\
\hline \multicolumn{15}{|l|}{ Firmicutes } \\
\hline Clostridiaceae & 2.6 & $(7.2)$ & 1.7 & 3.4 & - & 0.3 & 4.0 & 0.02 & 0.8 & 4.4 & - & 2.9 & 2.0 & - \\
\hline Clostridium & 2.6 & $(7.2)$ & 1.7 & 3.4 & - & 0.3 & 4.0 & 0.02 & 0.8 & 4.4 & - & 2.9 & 2.0 & - \\
\hline Enterococcaceae & 1.5 & $(2.2)$ & 1.7 & 1.3 & - & 0.9 & 1.8 & - & 0.7 & 2.3 & 0.09 & 1.6 & 1.1 & - \\
\hline Enterococcus & 1.5 & $(2.2)$ & 1.7 & 1.3 & - & 0.9 & 1.8 & - & 0.7 & 2.3 & 0.08 & 1.6 & 1.1 & - \\
\hline Erysipelotrichaceae & 5.2 & $(8.7)$ & 5.4 & 5.1 & - & 2.4 & 7.0 & - & 4.4 & 6.1 & - & 3.7 & 9.0 & - \\
\hline Lachnospiraceae & 22.0 & $(22.0)$ & 26.0 & 18.6 & - & 17.6 & 24.6 & - & 25.7 & 18.2 & - & 16.6 & 35.1 & 0.14 \\
\hline Blautia & 3.0 & $(7.6)$ & 5.4 & 0.9 & - & 0.6 & 4.4 & - & 0.7 & 5.2 & - & 0.9 & 8.1 & - \\
\hline Coprococcus & 0.8 & (2.6) & 0.7 & 1.0 & - & 0.0 & 1.3 & 0.01 & 0.0 & 1.6 & 0.12 & 0.2 & 2.3 & - \\
\hline Peptostreptococcaceae & 1.2 & $(2.0)$ & 2.3 & 0.3 & 0.02 & 0.1 & 1.9 & 0.007 & 0.6 & 1.9 & 0.14 & 0.7 & 2.4 & 0.08 \\
\hline Ruminococcaceae & 0.6 & $(1.1)$ & 0.9 & 0.4 & 0.12 & 0.4 & 0.7 & - & 0.4 & 0.8 & - & 0.6 & 0.5 & - \\
\hline Streptococcaceae & 5.7 & $(11.8)$ & 2.5 & 8.4 & - & 3.3 & 7.1 & - & 3.0 & 8.4 & - & 4.9 & 7.6 & - \\
\hline Streptococcus & 5.7 & $(11.8)$ & 2.5 & 8.3 & - & 3.3 & 7.1 & - & 2.9 & 8.4 & - & 4.9 & 7.6 & - \\
\hline Veillonellaceae & 4.7 & (6.9) & 5.2 & 4.3 & - & 1.2 & 6.8 & 0.02 & 1.6 & 7.8 & 0.02 & 3.4 & 7.7 & - \\
\hline Veillonella & 4.6 & (6.9) & 5.0 & 4.3 & - & 1.2 & 6.7 & 0.02 & 1.6 & 7.6 & 0.03 & 3.4 & 7.7 & - \\
\hline \multicolumn{15}{|l|}{ Verrucomicrobia } \\
\hline Verrucomicrobiaceae & 0.6 & $(2.2)$ & 0.9 & 0.3 & 0.06 & 0.4 & 0.7 & - & 0.3 & 0.9 & - & 0.8 & 0.0 & 0.01 \\
\hline Akkermansia & 0.6 & $(2.2)$ & 0.9 & 0.3 & 0.06 & 0.4 & 0.7 & - & 0.3 & 0.9 & - & 0.8 & 0.0 & 0.01 \\
\hline \multicolumn{15}{|l|}{ Proteobacteria } \\
\hline Enterobacteriaceae & 11.8 & $(11.1)$ & 9.6 & 13.7 & - & 10.7 & 12.5 & - & 12.5 & 11.2 & - & 11.8 & 11.9 & - \\
\hline Escherichia_Shigella & 10.5 & $(11.5)$ & 8.8 & 11.9 & - & 10.4 & 10.5 & - & 12.3 & 8.7 & - & 10.4 & 10.7 & - \\
\hline Pasteurellaceae & 0.2 & $(0.8)$ & 0.1 & 0.3 & - & 0.0 & 0.4 & 0.09 & 0.1 & 0.4 & - & 0.2 & 0.2 & - \\
\hline Haemophilus & 0.2 & $(0.8)$ & 0.1 & 0.3 & - & 0.0 & 0.4 & 0.09 & 0.1 & 0.4 & - & 0.2 & 0.2 & - \\
\hline
\end{tabular}

SD, standard deviation. Differential abundance test conducted using Metastats algorithm. P-values $>0.15$ not shown. Taxa were excluded from this analysis if they did not exceed $1 \%$ relative abundance in at least 1 sample, or were not present in at least 3 infants.

Although no clear consensus has been reached, many studies have reported inverse associations between early-life pet exposure and allergic disease. In a questionnaire study of over 2000 Swedish children, exposure to pets during the first year of life was associated with a lower prevalence of allergic rhinitis and asthma at school age [2]. Similarly in an American prospective birth cohort, exposure to 2 or more dogs or cats in the first year of life was found to reduce subsequent risk of allergic sensitization to multiple allergens during childhood [1]. Whether these associations can be attributed to changes in the infant gut microbiota remains to be seen. Sharing of specific microbes between pet and owner has been occasionally reported in adults [30-32], but colonization of the infant gut has rarely been studied in relation to pets. Using targeted methods to identify specific organisms, it has been reported that the presence of household pets does not influence colonization by Lactobacillus, E. coli, or C. difficile [23,33,34]. Ours is the first comprehensive profiling study to address the impact of pets on the infant gut microbiome as a whole. 

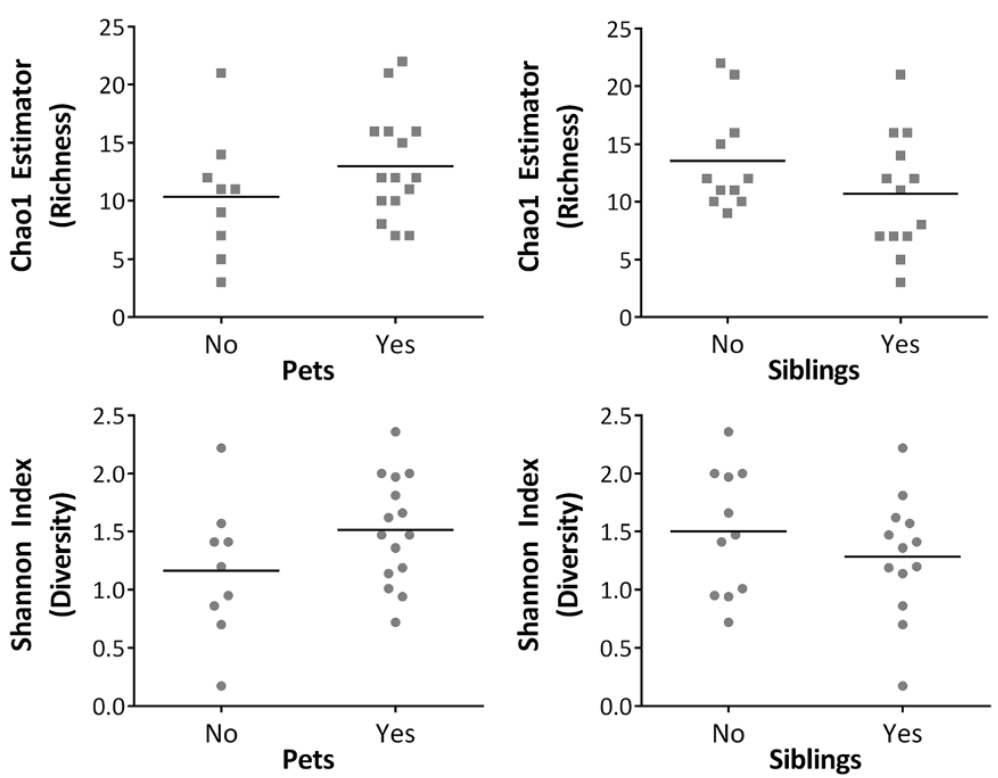

Figure 2 Richness and diversity of infant fecal microbiota according to the presence of household pets and siblings. Richness (Chao 1 estimator) and diversity (Shannon Index) were calculated from $16 \mathrm{~S}$ rRNA sequencing data (see Methods and Table 3).

Similar to household pets, the presence of older siblings has been associated with a reduced risk of atopic disease. Indeed, it was David Strachan's landmark paper on the inverse association between hay fever and household size (especially older siblings) that inspired the hygiene hypothesis [5]. Similar associations have since been reported around the world for both asthma [2] and food allergy [21]. Although frequently suggested as the underlying mechanism for these associations, there is only limited evidence that contact with siblings alters the infant gut microbiota. Using targeted or culture-based methods, others have shown that infants with older siblings have slightly higher numbers of Bifidobacteria [23], delayed colonization by Clostridium species [22], and increased colonization by Staphylococcus aureus [35], with no difference in C. difficile colonization [28]. Until now, no

Table 3 Infant fecal microbiota richness and diversity according to household pets and siblings

\begin{tabular}{|c|c|c|c|c|c|c|c|}
\hline & \multirow[b]{2}{*}{$\mathbf{N}$} & \multicolumn{3}{|c|}{$\begin{array}{c}\text { Chao1 Estimate: } \\
\text { Richness }\end{array}$} & \multicolumn{3}{|c|}{$\begin{array}{c}\text { Shannon index: } \\
\text { Diversity }\end{array}$} \\
\hline & & Mean & (SD) & $p$ & Mean & (SD) & $p$ \\
\hline Overall & 24 & 12 & (4.5) & & 1.38 & $(0.5)$ & \\
\hline \multicolumn{8}{|l|}{ Pets } \\
\hline No & 9 & 10.3 & (5.3) & 0.21 & 1.16 & (0.59) & 0.12 \\
\hline Yes & 15 & 13.0 & (4.6) & & 1.51 & $(0.46)$ & \\
\hline \multicolumn{8}{|c|}{ Older siblings } \\
\hline No & 11 & 13.5 & $(4.5)$ & 0.16 & 1.50 & $(0.54)$ & 0.34 \\
\hline Yes & 13 & 10.7 & (5.1) & & 1.29 & $(0.52)$ & \\
\hline
\end{tabular}

$\mathrm{SD}$, standard deviation. Comparison by unpaired, 2-sided t-test. study has reported the impact of siblings on the overall community structure of the gut microbiota.

Thus, despite the vast amount of evidence that household pets and siblings protect against allergic disease, and the widespread consensus that microbial exposure underlies these associations, ours is the first study to directly assess the impact of pets and siblings on the community composition and diversity of infant gut microbiota. We observed that while microbiota richness and diversity tended to be increased in infants living with pets, the opposite was true for infants with older siblings. Pets and siblings also appeared to select for distinct assemblages of gut microbes, possibly because they harbor and transmit different organisms (e.g. microbes from the outdoor environment, schools or daycares, and organisms from the normal animal or human microbiota). Transmission of microbes to the infant could occur through direct contact, or through intermediate reservoirs in the home environment (such as house dust or the maternal microbiome) [36,37]. Also, in contrast to a previous study [28], we found that $C$. difficile tended to be more prevalent among infants living with pets, and less prevalent among infants with siblings. Despite these apparently opposing influences, both pets and siblings are presumably protective against allergic disease (although this remains to be confirmed in our cohort, once the participants are old enough to evaluate atopic outcomes).

Collectively, this evidence suggests that simplified measures of microbiota diversity may be insufficient or even misleading, for the purposes of evaluating atopic disease risk and related biological mechanisms. Indeed, conflicting 


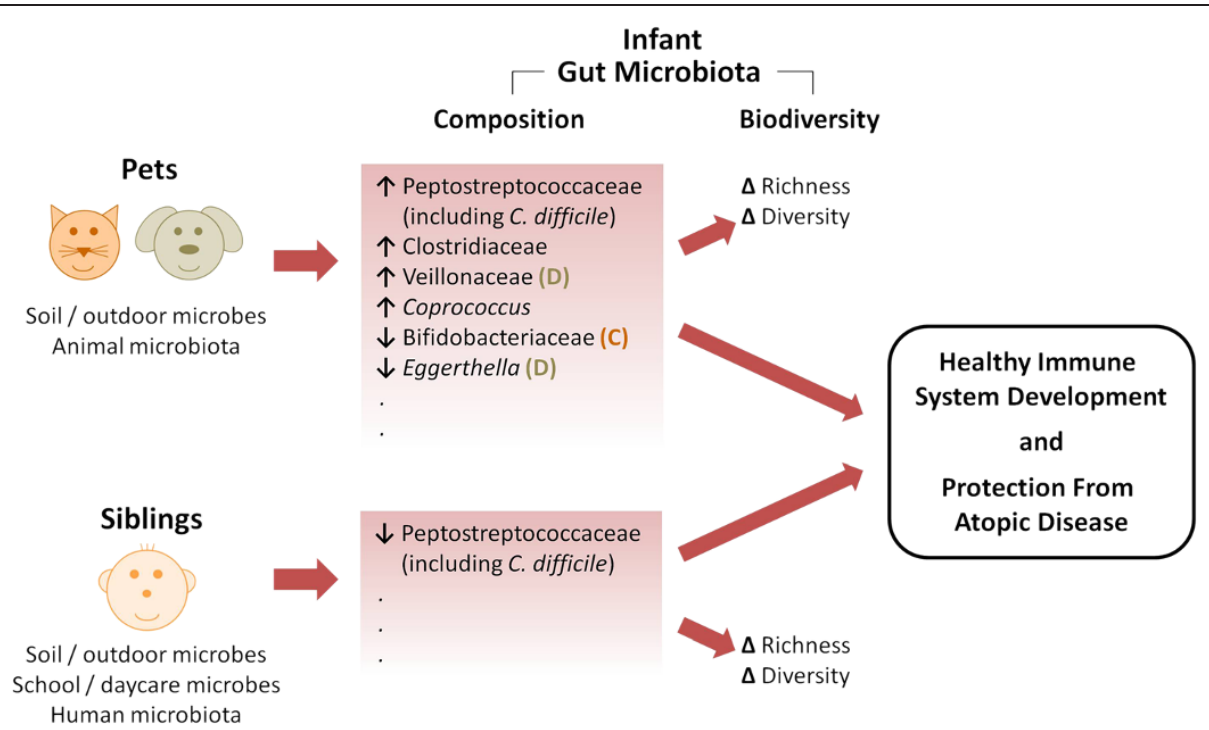

Figure 3 Model for the possible influence of pets and siblings on infant gut microbiota and subsequent development of atopic disease. Household pets ( $D$, dogs; $C$, cats) and siblings increase infant exposure to environmental microbes, promoting enrichment for distinct combinations of organisms within the gut microbiota; overall richness and diversity are also impacted. Despite favoring different microbiota profiles, the net effect of both pets and siblings is to promote healthy immune system development and protect against atopic disease. Further research is required to characterize the underlying biological mechanisms.

reports have indicated that both low and high infant gut microbiota diversity are associated with atopic eczema [7,38], illustrating the limited clinical value of these measures. The observation that two protective exposures apparently select for different combinations of microbes indicates that multiple "healthy" microbiota profiles are possible, perhaps due to functional redundancy among different organisms. As others have suggested, this functional redundancy may obviate the need for "keystone species" and high microbial diversity [15,39].

As the microbiota of domestic dogs, cats and other companion animals continue to become better defined by modern methods [40-42], the ability to resolve their microbial contributions to other microbial communities will improve. Because of the great degree of overlap at the genus-level between human- and pet-associated microbiota, sequencing approaches that yield species-level or even strain-level resolution are ultimately needed to differentiate these communities. In the meantime, algorithms to establish robust associations have already been demonstrated using sequence data of coarser taxonomic resolution [43-45]).

The major strengths of this study are the application of modern high-throughput sequencing technology to profile the gut microbiota of healthy infants, and the prospective collection of detailed exposure data. Our combined use of 16S rRNA sequencing and targeted qPCR analysis permitted the integration of reliable species-level data into the framework of comprehensive, culture-independent microbiome analysis. In addition, our finding that cats and dogs seem to favour enrichment of different organisms in the gut microbiota indicates that "pet exposure" is complex and should be defined as specifically as possible in population health studies in order to support future analyses.

The main limitation of this study is sample size; despite being relatively large among infant gut microbiota studies (many of which have comprised fewer than 15 infants [46-52]), we had insufficient power to detect differences according to type of pet or number of siblings. Also, we could not adjust for the simultaneous effects of multiple exposures; since the majority $(>80 \%)$ of infants without siblings in this cohort happened to live with pets, it is possible that pet exposure may be driving the siblingassociated differences observed in the current study. Further research is required to establish the independent and combined effects of these and other exposures, including potential confounders such as antibiotic use, caesarean delivery or breastfeeding $[53,54]$. These deficiencies will be addressed in our ongoing research within the full CHILD cohort, where longitudinal sampling and clinical evaluation of over 2000 infants is anticipated, and multivariate analyses will be possible.

\section{Conclusions}

In summary, this study provides new evidence that earlylife exposure to pets and siblings may influence the overall diversity and composition of the infant gut microbiota, with potential implications for the development of atopy (Figure 3). Allergic diseases have reached epidemic proportions in recent decades, and our research supports the 
hypothesis that modifiable environmental exposures may be responsible, through their impact on the gut microbiota. Our findings also emphasize the complexity of these associations, and underscore the need for further research.

\section{Additional file}

Additional file 1: Prevalence of dominant bacterial taxa in infant stool, according to household pets and siblings.

\section{Abbreviations}

CHILD: Canadian Healthy Infant Longitudinal Development Study; OTU: Operational taxonomic unit; qPCR: Quantitative polymerase chain reaction.

\section{Competing interests}

The authors declare that they have no competing interests.

\section{Authors' contributions}

MBA analyzed data and drafted manuscript; TK processed samples; HM processed sequence data; CJF provided data interpretation; ABB coordinated subject recruitment and sample/data collection; DSG, JAS \& ALK conceptualized and designed the study; MRS and the CHILD investigators contributed to the design/execution of the CHILD birth cohort. All authors contributed to data interpretation, and critically reviewed and approved the manuscript.

\section{Acknowledgements}

The authors extend sincere appreciation to all study families and the CHILD research team. We also thank Brenda Koster for bioinformatics support. Additional CHILD study investigators include: R. Allen (Ryan Simon Fraser University), D. Befus (University of Alberta), M. Brauer (University of British Columbia), J. Brook (Environment Canada), M. Cyr (McMaster University), E. Chen (University of British Columbia), D. Daley (James Hogg iCAPTURE Centre), S. Dell (Hospital for Sick Children), J. Denburg (McMaster University), S. Elliott (University of Waterloo), H. Grasemann (Hospital for Sick Children), K. HayGlass (University of Manitoba), R. Hegele (University of Toronto), L. Holness (St. Michael's Hospital), M. Kobor (University of British Columbia), T. Kollmann (University of British Columbia), C. Laprise (Chicoutimi University Hospital), M. Larché (McMaster University), W. Lou (University of Toronto), J. Macri (McMaster University), P. Mandhane (University of Alberta), G. Miller (North Western University), R. Moqbel (University of Manitoba), T. Moraes (Hospital for Sick Children), P. Paré (University of British Columbia), C. Ramsey (University of Manitoba), F. Ratjen (Hospital for Sick Children), B. Ritchie (University of Alberta), A. Sandford (James Hogg iCAPTURE Centre), Jeremy Scott (University of Toronto), F. Silverman (University of Toronto), P. Subbarao (Hospital for Sick Children), S. Tebbutt (James Hogg iCAPTURE Centre), T. Takaro (Simon Fraser University), P. Tang (University of British Columbia), T. To (Hospital for Sick Children), and S. Turvey (University of British Columbia).

\section{Author details}

${ }^{1}$ Department of Pediatrics, University of Alberta, 3-527 Edmonton Clinic Health Academy 11405 - 87th Avenue, Edmonton, AB T6G IC9, Canada. ${ }^{2}$ Dalla Lana School of Public Health, University of Toronto, Toronto, ON, Canada. ${ }^{3}$ Cell \& Systems Biology, University of Toronto, Toronto, ON, Canada. ${ }^{4}$ Agriculture, Food \& Nutritional Sciences, University of Alberta, Edmonton, AB, Canada. ${ }^{5}$ Department of Medicine, McMaster University, Hamilton, ON, Canada. ${ }^{6}$ Pediatrics \& Child Health, University of Manitoba, Winnipeg, MB, Canada. ${ }^{7}$ Manitoba Institute of Child Health, Winnipeg, Canada.

Received: 5 November 2012 Accepted: 7 March 2013 Published: 22 April 2013

\section{References}

1. Ownby DR, Johnson CC, Peterson EL: Exposure to dogs and cats in the first year of life and risk of allergic sensitization at 6 to 7 years of age. JAMA 2002, 288:963-972

2. Hesselmar B, Aberg N, Aberg B, Eriksson B, Bjorksten B: Does early exposure to cat or dog protect against later allergy development? Clin Exp Allergy 1999, 29:611-617.
3. Litonjua AA, Milton DK, Celedon JC, Ryan L, Weiss ST, Gold DR: A longitudinal analysis of wheezing in young children: the independent effects of early life exposure to house dust endotoxin, allergens, and pets. J Allergy Clin Immunol 2002, 110:736-742

4. Ball TM, Castro-Rodriguez JA, Griffith KA, Holberg CJ, Martinez FD, Wright AL: Siblings, day-care attendance, and the risk of asthma and wheezing during childhood. N Engl J Med 2000, 343:538-543.

5. Strachan DP: Hay fever, hygiene, and household size. BMJ 1989, 299:1259-1260.

6. Wold AE: The hygiene hypothesis revised: is the rising frequency of allergy due to changes in the intestinal flora? Allergy 1998, 53:20-25.

7. Abrahamsson TR, Jakobsson HE, Andersson AF, Bjorksten B, Engstrand L, Jenmalm MC: Low diversity of the gut microbiota in infants with atopic eczema. J Allergy Clin Immunol 2012, 129:434-440. 440.

8. Kalliomaki M, Kirjavainen P, Eerola E, Kero P, Salminen S, Isolauri E: Distinct patterns of neonatal gut microflora in infants in whom atopy was and was not developing. J Allergy Clin Immunol 2001, 107:129-134.

9. Vebo HC, Sekelja M, Nestestog R, Storro O, Johnsen R, Oien T, et al: Temporal development of the infant gut microbiota in IgE sensitized and non-sensitized children determined by the GA-map infant array. Clin Vaccine Immunol 2011, 18:1326-1335.

10. Bisgaard H, Li N, Bonnelykke K, Chawes BL, Skov T, Paludan-Muller G, et al: Reduced diversity of the intestinal microbiota during infancy is associated with increased risk of allergic disease at school age. J Allergy Clin Immunol 2011, 128:646-652.

11. Nakayama J, Kobayashi T, Tanaka S, Korenori Y, Tateyama A, Sakamoto N, et al: Aberrant structures of fecal bacterial community in allergic infants profiled by 16S rRNA gene pyrosequencing. FEMS Immunol Med Microbio/ 2011, 63:397-406.

12. Penders J, Thijs C, van den Brandt PA, Kummeling I, Snijders B, Stelma F, et al: Gut microbiota composition and development of atopic manifestations in infancy: the KOALA Birth Cohort Study. Gut 2007, 56:661-667.

13. Vael C, Vanheirstraeten L, Desager KN, Goossens $H$ : Denaturing gradient gel electrophoresis of neonatal intestinal microbiota in relation to the development of asthma. BMC Microbiol 2011, 11:68.

14. Mulder IE, Schmidt B, Stokes CR, Lewis M, Bailey M, Aminov Rl, et al: Environmentally-acquired bacteria influence microbial diversity and natural innate immune responses at gut surfaces. BMC Biol 2009, 7:79.

15. Dicksved J, Floistrup H, Bergstrom A, Rosenquist M, Pershagen G, Scheynius A et al: Molecular fingerprinting of the fecal microbiota of children raised according to different lifestyles. Appl Environ Microbio/ 2007, 73:2284-2289.

16. van Nimwegen FA, Penders J, Stobberingh EE, Postma DS, Koppelman GH, Kerkhof $M$, et al: Mode and place of delivery, gastrointestinal microbiota, and their influence on asthma and atopy. J Allergy Clin Immunol 2011, 128:948-955.

17. Bjorksten B, Sepp E, Julge K, Voor T, Mikelsaar M: Allergy development and the intestinal microflora during the first year of life. J Allergy Clin Immunol 2001, 108:516-520.

18. Johansson MA, Sjogren YM, Persson JO, Nilsson C, Sverremark-Ekstrom E: Early colonization with a group of Lactobacilli decreases the risk for allergy at five years of age despite allergic heredity. PLoS One 2011, 6:e23031.

19. Murray CS, Tannock GW, Simon MA, Harmsen HJ, Welling GW, Custovic A, et al: Fecal microbiota in sensitized wheezy and non-sensitized non-wheezy children: a nested case-control study. Clin Exp Allergy 2005, 35:741-745.

20. Lodrup Carlsen KC, Roll S, Carlsen KH, Mowinckel P, Wijga AH, Brunekreef B, et al: Does pet ownership in infancy lead to asthma or allergy at school age? Pooled analysis of individual participant data from 11 European birth cohorts. PLoS One 2012, 7:e43214.

21. Koplin JJ, Dharmage SC, Ponsonby AL, Tang ML, Lowe AJ, Gurrin LC, et al: Environmental and demographic risk factors for egg allergy in a population-based study of infants. Allergy 2012, 67:1415-1422.

22. Adlerberth I, Strachan DP, Matricardi PM, Ahrne S, Orfei L, Aberg N, et al: Gut microbiota and development of atopic eczema in 3 European birth cohorts. J Allergy Clin Immunol 2007, 120:343-350.

23. Penders J, Thijs C, Vink C, Stelma FF, Snijders B, Kummeling I, et al: Factors influencing the composition of the intestinal microbiota in early infancy. Pediatrics 2006, 118:511-521.

24. Ariefdjohan MW, Savaiano DA, Nakatsu CH: Comparison of DNA extraction kits for PCR-DGGE analysis of human intestinal microbial communities from fecal specimens. Nutr J 2010, 9:23. 
25. Maughan H, Wang PW, Diaz CJ, Fung P, Gong Y, Donaldson SL, et al: Analysis of the cystic fibrosis lung microbiota via serial illumina sequencing of bacterial 16S rRNA hypervariable regions. PLoS One 2012, 7:e45791.

26. Edgar RC: Search and clustering orders of magnitude faster than BLAST. Bioinformatics 2010, 26:2460-2461.

27. Pruesse E, Quast C, Knittel K, Fuchs BM, Ludwig W, Peplies J, et al: SILVA: a comprehensive online resource for quality checked and aligned ribosomal RNA sequence data compatible with ARB. Nucleic Acids Res 2007, 35:7188-7196.

28. Colwell RK: Biodiversity: Concepts, Patterns, and Measurement. Princeton University Press. The Princeton Guide to Ecology; 2009:257-263.

29. Caporaso JG, Kuczynski J, Stombaugh J, Bittinger K, Bushman FD, Costello EK, et al: QIIME allows analysis of high-throughput community sequencing data. Nat Methods 2010, 7:335-336.

30. Damborg P, Nielsen SS, Guardabassi L: Escherichia coli shedding patterns in humans and dogs: insights into within-household transmission of phylotypes associated with urinary tract infections. Epidemiol Infect 2009, 137:1457-1464.

31. Johnson JR, Clabots C, Kuskowski MA: Multiple-host sharing, long-term persistence, and virulence of Escherichia coli clones from human and animal household members. J Clin Microbiol 2008, 46:4078-4082.

32. Stokholm J, Schjorring S, Pedersen L, Bischoff AL, Folsgaard N, Carson CG, et al: Living with cat and dog increases vaginal colonization with E. Coli in pregnant women. PLoS One 2012, 7:e46226.

33. Ahrne S, Lonnermark E, Wold AE, Aberg N, Hesselmar B, Saalman R, et al: Lactobacilli in the intestinal microbiota of Swedish infants. Microbes Infect 2005, 7:1256-1262.

34. Nowrouzian F, Hesselmar B, Saalman R, Strannegard IL, Aberg N, Wold AE, et al: Escherichia coli in infants' intestinal microflora: colonization rate, strain turnover, and virulence gene carriage. Pediatr Res 2003, 54:8-14.

35. Lindberg E, Adlerberth I, Matricardi P, Bonanno C, Tripodi S, Panetta V, et al: Effect of lifestyle factors on Staphylococcus aureus gut colonization in Swedish and Italian infants. Clin Microbiol Infect 2011, 17:1209-1215.

36. Thum C, Cookson AL, Otter DE, McNabb WC, Hodgkinson AJ, Dyer J, et al: Can nutritional modulation of maternal intestinal microbiota influence the development of the infant gastrointestinal tract? J Nutr 2012, 142:1921-1928

37. Konya T: Is house dust a reservoir for infant gut bacteria?. Dalla Lana School of Public Health, University of Toronto: Masters in Public Health; 2012.

38. Nylund L, Satokari R, Nikkila J, Rajili-Stojanovi M, Kalliomaki M, Isolauri E, et al: Microarray analysis reveals marked intestinal microbiota aberrancy in infants having eczema compared to healthy children in at-risk for atopic disease. BMC Microbiol 2013, 13:12.

39. Ley RE, Peterson DA, Gordon Jl: Ecological and evolutionary forces shaping microbial diversity in the human intestine. Cell 2006, 124:837-848.

40. Minamoto Y, Hooda S, Swanson KS, Suchodolski JS: Feline gastrointestinal microbiota. Anim Health Res Rev 2012, 13:64-77.

41. Dewhirst FE, Klein EA, Thompson EC, Blanton JM, Chen T, Milella L, et al: The canine oral microbiome. PLoS One 2012, 7:e36067.

42. Weese JS: The canine and feline skin microbiome in health and disease. Vet Dermatol 2013, 24:137-145.

43. Flores GE, Bates ST, Knights D, Lauber CL, Stombaugh J, Knight R, et al: Microbial biogeography of public restroom surfaces. PLoS One 2011, 6:e28132.

44. Knights D, Kuczynski J, Charlson ES, Zaneveld J, Mozer MC, Collman RG, et al: Bayesian community-wide culture-independent microbial source tracking. Nat Methods 2011, 8:761-763.

45. Bowers RM, Sullivan AP, Costello EK, Collett JL Jr, Knight R, Fierer N: Sources of bacteria in outdoor air across cities in the Midwestern United States. Appl Environ Microbiol 2011, 77:6350-6356.

46. Bezirtzoglou E, Tsiotsias A, Welling GW: Microbiota profile in feces of breast- and formula-fed newborns by using Fluorescence In situ Hybridization (FISH). Anaerobe 2011, 17:478-482.

47. Harmsen HJ, Wildeboer-Veloo AC, Raangs GC, Wagendorp AA, Klijn N, Bindels $\mathrm{JG}$, et al: Analysis of intestinal flora development in breast-fed and formula-fed infants by using molecular identification and detection methods. J Pediatr Gastroenterol Nutr 2000, 30:61-67.

48. Hong PY, Lee BW, Aw M, Shek LP, Yap GC, Chua KY, et al: Comparative analysis of fecal microbiota in infants with and without eczema. PLoS One 2010, 5:e9964

49. Palmer C, Bik EM, DiGiulio DB, Relman DA, Brown PO: Development of the human infant intestinal microbiota. PLoS Biol 2007, 5:e177.
50. Roger LC, Costabile A, Holland DT, Hoyles L, McCartney AL: Examination of faecal Bifidobacterium populations in breast- and formula-fed infants during the first 18 months of life. Microbiology 2010, 156:3329-3341.

51. Stark PL, Lee A: The microbial ecology of the large bowel of breast-fed and formula-fed infants during the first year of life. J Med Microbio/ 1982, 15:189-203.

52. Turroni F, Peano C, Pass DA, Foroni E, Severgnini M, Claesson MJ, et al: Diversity of Bifidobacteria within the Infant Gut Microbiota. PLoS One 2012, 7:e36957.

53. Azad MB, Kozyrskyj AL: Perinatal programming of asthma: the role of gut microbiota. Clin Dev Immunol 2012, $201(2): 932072$.

54. Azad MB, Konya T, Maughan H, Guttman DS, Field CJ, Chari RS, et al: Gut microbiota of healthy Canadian infants: profiles by mode of delivery and infant diet at 4 months. CMAJ 2013. 185(5):385-394 doi:10.1503/ cmaj.121189.

doi:10.1186/1710-1492-9-15

Cite this article as: Azad et al:: Infant gut microbiota and the hygiene hypothesis of allergic disease: impact of household pets and siblings on microbiota composition and diversity. Allergy, Asthma \& Clinical

Immunology 2013 9:15.

\section{Submit your next manuscript to BioMed Central and take full advantage of:}

- Convenient online submission

- Thorough peer review

- No space constraints or color figure charges

- Immediate publication on acceptance

- Inclusion in PubMed, CAS, Scopus and Google Scholar

- Research which is freely available for redistribution 